\title{
LA EFICACIA DE LAS REDES EN LA TRANSFERENCIA DE BIENES SIMBÓLICOS: EL EJEMPLO DEL MODERNISMO HISPANOAMERICANO
}

The efficiency of the networks in the transfer of symbolic goods: The example of Spanish-American modernism

Claudio Maiz*

Resumen

Pretendemos hacer funcionar la metodología de las redes en el campo de los estudios literarios, realizando inicialmente una revisión de las nociones de red y algunas de las orientaciones teóricas existentes. El objetivo es poner de manifiesto la manera como las redes permiten la transferencia de tópicos culturales (ideas, modas, tendencias, etc.) prescindiendo de contactos personales o no siendo estos determinantes. Asimismo, evaluamos la manera cómo las redes preparan los escenarios en los cuales puede una idea tornarse triunfante y llegar a imponerse en un determinado espacio. El caso que veremos, con valor ejemplificador solamente, será el del modernismo hispanoamericano, pero no se agota en él la capacidad heurística de las redes, desde luego.

Palabras clave: Redes intelectuales, transferencia de bienes simbólicos, modernismo literario.

Abstract

In this work we try to make the methodology of the networks work in the field of the literary studies. Nevertheless, we have initially carried out a review of the network's notions and we discussed some of the existing theoretical orientations. The general aim is to reveal the ways allowed by the networks, across their frameworks, the transfer of cultural topics (ideas, modes, trends, etc.) by doing it without personal contacts or by not being these determinants. Also, the way the networks prepare the scenario in which an idea can emerge triumphant and get to be imposed in a certain space. The case that we will see, with only an exemplary value, will be the one of the Spanish-American modernism, but the heuristic capacity of the networks certainly does not run out with it.

Key words: Intellectual networks, transfer of symbolic goods, literary modernism.

TECNOLOGÍA, SOCIEDAD Y CAMBIO HISTÓRICO

No es la interconexión "real" de las "cosas", sino la interconexión conceptual de los
problemas lo que define al ámbito de las diferentes ciencias. Alli donde se trata un
nuevo problema mediante un método nuevo emerge una nueva ciencia. Max Weber (1982).

El epígrafe de Max Weber es un buen punto de partida, especialmente el primer concepto sobre la "interconexión 'real' de las 'cosas' y la interconexión conceptual de los problemas", ambas perspectivas como límites de la definición de la diferencia entre las ciencias. Es decir, lo que define los problemas de una ciencia es la capacidad de interconectar no lo tangible de lo real (solamente, agregaríamos de nuestra parte), sino nuestras percepciones, ideas o prejuicios 


\section{Claudio Maíz}

sobre aquello que no está resuelto y merece serlo. Queremos subrayar la eventualidad de prescindir del orden de las "cosas" para situarnos en un orden diferente, en el de los discursos que dan cuenta de ellas. ${ }^{1}$ Esta es una perspectiva que pretendemos desarrollar en el presente trabajo, tomando en cuenta que lugares, medios y redes (Prochasson, 1993) corresponden a dimensiones que prescinden de la interconexión "real" ya no de "cosas", sino de "cualquier cosa". Ha sido la teoría del actor-red proveniente de la sociología de la ciencia la que ha facilitado un enfoque más actual de las apreciaciones precedentes. Por actor-red se entiende que un objeto científico-técnico es "el resultado de la mezcla de entidades humanas y naturales pero que actúa socialmente con las características de un actor situado en dinámicas sociales y leyes naturales, gracias a las posibilidades instrumentadas de ambas". Es así como la noción red ha venido a sustituir a la de sistema, en virtud de que el sistema pone en relación los elementos de una parte delimitada de la realidad, pero sin jerarquía precisa, mientras que la red toma los elementos de manera interrelacionados "por medio de circulación de información". El actor-red no es reducible ni a un simple actor ni a una red. Su composición es heterogénea con elementos ligados, mutuamente, durante un periodo de tiempo. Ya tendremos oportunidad de apreciar que la noción de actor-red se aviene mejor a un "pensamiento colectivo" en una pluralidad de voces que a la figura del autor (Arellano Hernández, 2003).

Consideramos necesario partir de un postulado que nos parece crucial para nuestros fines: la existencia de una relación conformada por los términos de tecnología, sociedad y cambio histórico. Si partimos de un nivel mayor de abstracción es por el hecho de que, probablemente, así sea posible elaborar las respuestas que pretendemos en torno a una red. En efecto, la imbricación de estos conceptos está en la base de la reflexión sobre la revolución de la tecnología de la información, que esencialmente — como se sabe - se trata de un fenómeno contemporáneo. Sin embargo, el modelo no ha operado únicamente en este periodo, sino que ha sido de utilidad para la extracción de conclusiones respecto de los cambios culturales, en sentido amplio, y las redes. ${ }^{2}$

\footnotetext{
1 "El orden, es a la vez, lo que se da en las cosas como su ley interior, la red secreta según la cual se miran en cierta forma unas a otras, y lo que no existe a no ser a través de la reja de una mirada, de una atención, de un lenguaje; y sólo en las casillas blancas de este tablero se manifiesta en profundidad como ya estando ahí, esperando en silencio el momento de ser enunciado." (Foucault, 1988:5). Más recientemente, Laclau y Mouffe afirman que "una estructura discursiva no es una entidad meramente 'cognitiva' o 'contemplativa'; es una práctica articulatoria que constituye y organiza las relaciones sociales" (1987:109).

${ }^{2}$ Adelantemos, por ahora, el enfoque de Aldo Ferrer en su Historia de la globalización, en relación con el Primer Orden Mundial: "La interacción entre los planos de la cultura, la religión, la política y la economía impulsaron nuevos factores endógenos del crecimiento económico. Estos, a su vez, sustentaron inéditos elementos intangibles de poder. El reparto, entre las potencias atlánticas, del dominio del espacio europeo y del emergente orden mundial se fue 


\section{La eficacia de las redes en la transferencia de bienes simbólicos}

Dentro de la teoría comunicacional más reciente es, entonces, donde la noción de red ha adquirido categoría explicativa de los fenómenos sociales contemporáneos. En la línea iniciada por Marshall McLuhan - a quien se debe a partir de los años 50-60 del siglo pasado la historia de la fuerza estructurante de las técnicas de comunicación - continuada por Manuel Castells, principalmente, ha sido destacada la capacidad de la revolución tecnológica de la comunicación para penetrar en todo el ámbito de la actividad humana. "La tecnología no determina la sociedad", dice Castells; sin embargo, matiza, agregando que "la plasma". Pero así como la sociedad sólo plasma la tecnología, la sociedad tampoco determina la tecnología: "la utiliza". Se trata de una interacción dialéctica entre sociedad y tecnología, a la manera metodológica de historiadores como Fernand Braudel (Castells, 1998:31). ${ }^{3}$ Para la teoría de la comunicación, la noción de red adquiere un extraordinario poder explicativo de los cambios sociales. Según Manuel Castells, la exploración de las estructuras sociales emergentes lo llevan a la conclusión de que "como tendencia histórica, las funciones y los procesos dominantes de la era de la información cada vez se organizan más en torno a redes" (1998a:505). Se trata de una nueva morfología de las sociedades contemporáneas que han permitido a Castells ir más allá en sus proposiciones al pensar en un Estado-Red (1998b).

Pues bien, aunque se trate rigurosamente de un fenómeno contemporáneo a la luz de una nueva revolución tecnológica que altera los procesos de producción, la experiencia, el poder y la cultura, la lógica de enlace supuesta en la red puede indagarse en otros periodos históricos. En tanto modelo de organización informal, la red ha existido en otros tiempos y espacios, pese a que "el nuevo paradigma de la tecnología de la información proporciona la base material para que su expansión cale toda la estructura social", dice Castells (1998a:505). Sostenemos que es dentro de la ecuación sociedad, tecnología y cambio histórico, donde podemos dar cuenta de la manera como una idea estética se transfiere de un campo intelectual a otro. A decir verdad, el intento,

asentando, en una compleja red de componentes tangibles e intangibles del poder. /.../Aparecieron, de este modo, factores endógenos del crecimiento que fueron ganando importancia a lo largo del Primer Orden Económico Mundial. Surgieron nuevas redes, eslabonamientos y relaciones entre la actividad directamente vinculada al tráfico comercial y su financiamiento con la producción interna de manufacturas y alimentos" (1996:396).

${ }^{3}$ Conviene recordar aquí que otra "tecnología" como la escritura no provoca efectos directos sobre el cambio intelectual y social; la cultura escrita no puede verse en términos de consecuencias. "Lo que importa es lo que la gente hace con la escritura, y no lo que la escritura hace a la gente. La cultura escrita no genera un nuevo modo de pensar; pero el hecho de contar con un registro escrito posiblemente le permite a la gente hacer algo que antes no podía hacer: revisar, estudiar, reinterpretar y demás. Análogamente la cultura escrita no origina el cambio social, la modernización ni la industrialización. /.../ La escritura es importante por lo que permite hacer a la gente: alcanzar sus objetivos o vislumbrar objetivos nuevos”. Olson, D.R., Hildyard, A., y Torrance, N. (1985:13). 


\section{Claudio Maíz}

en lo que respecta a América Latina, de extraer conclusiones plausibles de la relación entre avances tecnológicos y cambios en el mundo de la cultura y el pensamiento no ha ido más allá de la segunda mitad del siglo XX. Estudios como los de Arturo Roig sobre las nuevas discursividades en el siglo XIX no abundan. $^{4}$ De ello puede exceptuarse el trabajo de Susana Rotker sobre la crónica modernista, en el que se propuso ahondar dialécticamente la época y ciertos textos producidos, es decir, leer a través de las crónicas "otra forma de las prácticas discursivas: con signos de interacción entre institución, sociedad y formas de discurso" (1992:16). También hay que recordar la difundida tesis de Benedict Anderson sobre los orígenes culturales del nacionalismo. Anderson admite una convergencia del capitalismo y la tecnología impresa (el nudo de su tesis). Dicha confluencia, "en la fatal diversidad del lenguaje humano hizo posible una nueva forma de comunidad imaginada, que en su morfología básica preparó el escenario para la nación moderna (1997:75). A su vez, el historiador Walter Bose, igualmente, ha entrevisto el problema, en su historia de las comunicaciones, cuando advierte que el envío de una misiva, en palabras o signos convenidos, es el objetivo esencial de los sistemas de comunicación y agrega: "Su evolución histórica se halla ligada al desarrollo del comercio y a los progresos de la técnica y de la industria (1966:575).

Por último, cabe incorporar aquí el intento - por cierto excesivo y de resultados dudosos - de escribir una "historia global del mundo" a partir de las redes humanas, como es el caso de J.R. McNeill y William H. McNeill. Si enorme es el esfuerzo, no dejan de ser atractivas y pertinentes a nuestros propósitos las razones por las cuales los autores insisten en concretar una "historia brevísima de la especie humana". En efecto, subsidiarios en cierto modo de Fernand Braudel e Immanuel Wallerstein, los autores reconocen que el estado, tradicionalmente unidad de análisis de la historia, ha perdido importancia en tanto tal. En su reemplazo se consolida una perspectiva histórica que se extienda a todo el planeta y no sólo a una nación o región. Aunque nada de ello sea novedoso, tal como ellos mismos lo admiten, ya que la internacionalización ha sido una acción que ha afectado a los asuntos humanos desde hace miles de años. Así, el comercio y la inmigración se cuentan entre los propulsores más antiguos de la historia. Una idea que no puede pasar desapercibida para nosotros en cuanto a los cambios que acontecen en el campo de las ideas habla de una vinculación entre las "nuevas infraestructuras de la

\footnotetext{
${ }^{4}$ Arturo Roig ensayó una vinculación entre los medios técnicos y las formas discursivas en el siglo XIX. Precisamente, "el periodismo de ensayo" o ensayismo, en general, es una forma discursiva inherente "al desarrollo histórico de los sistemas de comunicación, cuya tecnología surge como exigencia de nuevas manifestaciones discursivas y, a la vez, condiciona a estas mismas. El siglo XIX fue testigo, en este sentido, de una de las grandes revoluciones tecnológicas de la Edad Moderna, el nacimiento de la prensa periódica que terminó por generalizarse, a fines de la época, como prensa diaria" (1986).
} 
información" y "la competencia en el mercado de ideas" (McNeill, R., McNeill, William H., 2004:304). ${ }^{5}$ Todavía dentro del campo de la historiografía cultural, no está de más recordar el libro de Asa Briggs y Peter Burke, De Gutenberg a Internet. Una historia social de los medios de comunicación (2002) en el que se enfatiza la necesidad de contar con la política, la economía y la tecnología en cualquier historia social y cultural sin embargo, se previene sobre el peligro de caer en el determinismo tecnológico. La tesis central de Peter Burke consiste en que quienes se ocupan de la comunicación y la cultura no pueden prescindir de la historia y los historiadores deben tomar más en serio la teoría de la comunicación (2002:12). Recomendación que, por cierto, no ha sido muy incorporada por los historiadores.

Los puntos que se indican a continuación constituyen hipótesis que demandan una mayor demostración, sin embargo, contribuyen a nuestra argumentación y a aclarar nuestro objetivo que no es otro sino el de poner de manifiesto la manera como las redes permiten, a través de sus entramados, la transferencia de tópicos culturales (ideas, modas, tendencias, etc.) prescindiendo de contactos personales o no siendo estos determinantes. Asimismo, la manera como las redes preparan los escenarios en los cuales puede una idea tornarse triunfante y llegar a imponerse en un determinado espacio. El caso que veremos será el del modernismo hispanoamericano, pero no se agota en él la capacidad heurística de las redes, desde luego. En resumen, los puntos de partida de nuestras reflexiones son los siguientes

a. La red no es una lógica de enlace perteneciente nada más que a la era de la informática, sino que puede constatarse en otros periodos.

b. Las redes culturales funcionan, como la serie literaria en general, sin replicar mecánicamente ni la serie económica mundial ni sus derivaciones políticas o tecnológicas.

c. Por tanto, la morfología de la red no está determinada por el grado de desarrollo tecnológico alcanzado. Sin embargo, lo dicho es un punto de partida

\footnotetext{
${ }^{5}$ A propósito de la tesis que relaciona cambios en la infraestructura de la información y las ideas, los autores analizan el proceso de la esclavitud entre 1790-1936: "La abolición logró en la esfera social lo que el aprovechamiento de los combustibles fósiles en el ámbito del trabajo propiamente dicho: una liberación histórica respecto del esfuerzo muscular. Fueron acontecimientos relacionados y más o menos simultáneos. El uso de energía inanimada hizo que disminuyera gradualmente la escasez de mano de obra y que los trabajadores forzados resultaran menos atractivos. Facilitó la comunicación de ideas antiesclavistas. También hizo más sencilla la imposición de la moral emancipadora europea en Asia y África /.../ Las corrientes mundiales de crecimiento demográfico, de industrialización, de empleo de energía y de moral igualitaria fluyeron juntas para modificar la condición humana" (McNeill, R., McNeill, William H., 2004:291). Una argumentación similar se puede encontrar en Roberto Schwarz, cuando trata la inadecuación de la esclavitud en la sociedad liberal brasileña (2000). El tema ha sido revisado recientemente. Cfr., Palti (2004); Telles (2004), Maíz (2007).
} 


\section{Claudio Maíz}

necesario - pero no suficiente - para comprender las variaciones en los ciclos culturales, los cambios de preferencia ideológica, los revisionismos, etc. Mientras que la unidad mínima tecnológica en la red de la Era Informática está constituida por el bit, dentro del periodo 1875-1914, aproximadamente, la carta y la transmisión eléctrica del telégrafo ocupan ese lugar. Aun antes, grupos de intelectuales como Andrés Bello, Francisco de Miranda, Simón Bolívar, Carlos María de Alvear y Fray Servando Teresa de Mier, reunidos en Londres a comienzos del siglo XIX, actuaban bajo la lógica de la red. El proceso de urbanización, donde irrumpe históricamente la figura del intelectual, impacta significativamente sobre las formaciones culturales en red en América Latina, a través de nodos urbanos móviles - polos de religación- cuyos ejemplos paradigmáticos son Rubén Darío y José Martí, pero que pueden identificarse en muchos otros casos. Pedro Henríquez Ureña, Hélio Oiticica, Guillermo Cabrera Infante son sólo algunos ejemplos al azar de intelectuales migrantes que escriben desde nuevos nodos y articulan redes desde ciudades americanas o europeas.

d. La lógica de enlace no tiene una relación determinante con la base tecnológica, ya se ha dicho. Sin embargo, vale señalar que los estudios que se han ocupado de las redes intelectuales en América Latina no se han interrogado, en profundidad, sobre el funcionamiento y los mecanismos que intervienen en los enlaces. Se da por hecho que la red crea los vínculos, pero no hay interrogantes sobre la real incidencia que los mismos tienen sobre la producción intelectual ni el comportamiento individual.

e. Parte de la dificultad de operar con las redes se encuentra en lo intangible de los vínculos personales, por ejemplo los de la bohemia, y la pobreza de los archivos epistolares o personales de escritores o, incluso, de revistas latinoamericanas. Quizás, lo más importante: las ideas — cualquiera sea su contenido y alcance - no están entretejidas a través de sujetos individuales que las piensan y luego las difunden sin que medien componentes de naturaleza contextual, social, tecnológica, etc. Las redes son el lenguaje de los vínculos, es fundamentalmente un concepto vincular (Fleury, 2002). En definitiva, estas afirmaciones otorgan sentido a una posible ciencia de las redes en el campo de los estudios sobre la cultura, al menos como una hipótesis.

\section{CAMBIOS Y FUNCIÓN DE LAS REDES}

Hemos tomado la lógica de enlace de la red, desde la perspectiva comunicacional, como un punto de partida. También nos hemos ocupado de señalar otras perspectivas igualmente válidas. Convendría, ahora, retomar los dominios en los que se ha supuesto su real incidencia, es decir, el espacio problemático compuesto por la tecnología, la sociedad y el cambio, reiterando que se descarta cualquier determinismo. Darlo por cierto en el periodo correspondiente a la revolución tecnológica comunicacional, no nos exime de 


\section{La eficacia de las redes en la transferencia de bienes simbólicos}

pensar los términos específicos que adquiere en otro contexto histórico-cultural, como es el de fines del siglo XIX y comienzos del XX.

En efecto, la segunda gran oleada globalizadora se produce en la era del imperialismo, entre los años 1870-1914, como consecuencia de los grandes cambios demográficos, políticos y económicos. ${ }^{6}$ Un primer impulso unió las costas de los mares del mundo y las cuencas de los ríos por medio de la navegación marítima. Con los acontecimientos mencionados se inaugura la era del Atlántico y el declive del mare nostrum (el Mediterráneo) como escenario primordial de la historia. Un segundo impulso profundizó lo hecho por el primero y lo proyectó hacia tierra adentro. Esta fuerza tuvo como base tecnológica a los barcos de vapor, el ferrocarril y el telégrafo, como innovaciones fundamentales. La nota dominante en este segundo impulso globalizador la dan los incrementos en la movilidad de las personas, las mercancías y el dinero. Las movilizaciones masivas anteriores al siglo XIX (pueblos nómadas, trata de esclavos en el Atlántico, etc.) no tienen comparación con las que se producen en el nuevo ciclo abierto. Se estima que entre 1830 y 1914 más de cien millones de personas participaron en las gigantescas migraciones de la India, China y Europa (McNeill, J.R. y McNeill, W.H. 2004: 294). Como consecuencia de estos masivos desplazamientos se produce lo que J.R. McNeill y W. H. McNeill llaman una "condensación de la red" que contribuyó a propagar la explosión demográfica, formas políticas más representativas, identidades nacionalistas e industrialización (2004:298). Es la hora de los vientos huracanados de la modernización fáustica. ${ }^{7}$

\footnotetext{
6 "Los discursos panegíricos sobre el advenimiento de la "era global" se profieren, cada vez más, en una situación de atopía social. El propio término "globalización", préstamo de la lengua inglesa que designa el estado y el destino del mundo, ha sido adoptado por la mayoría de las lenguas del globo, en un tiempo récord, y sin beneficio de inventario. Términos de orígenes distintos parecen fundirse en su crisol: "universal", "cosmopolita", "mundial", "planetario". Hasta tal punto que casi se olvida el trasfondo de esta meteórica homologación. No obstante, aunque el vocablo evoca, indiscutiblemente, las nuevas modalidades de la interdependencia de las economías, así como de las culturas, la presentación de la "comunidad global" que conlleva remite a una particular forma de descomponer el proceso histórico de unificación del mundo. Este sesgo convierte un fenómeno de múltiples dimensiones, simbólicas y reales, en el zócalo de un pensamiento único, y le imprime un carácter de fatalidad" Mattelart (2000:13).

${ }^{7}$ Veamos de qué manera se entendía este modelo a comienzos del siglo XX en América Latina. Escribe, en 1910, Manuel Ugarte: "Emprendamos en todas partes la obra de vencer a la Naturaleza, imponiendo de un extremo a otro del continente la marcha triunfal del hombre. Las florestas impenetrables, los ríos que desbordan, las montañas inaccesibles y hasta los hoscos volcanes que nos fulminan tienen que ser dominados al fin. Poco importan los obstáculos. Más emocionante que las batallas /.../ pero mucho más gloriosa, es la lucha entre la especie y la creación, el duelo trágico entre la naturaleza y el genio" (1910:153). Por otro lado, J.R. McNeill y William H. McNeill ponen especial cuidado en exaltar la relación entre los grandes cambios tecnológicos y el estrechamiento y adensamiento de la red. Tres son las oleadas de las transformaciones tecnológicas: 1) el teléfono se inventó en 1870, el automóvil en 1890 y la radio
} 


\section{Claudio Maíz}

Entre 1784 a 1918 se produce una revolución comunicacional que combina un espectacular avance técnico de las comunicaciones en un tiempo relativamente corto. Este fenómeno técnico se ve acompañado por grandes relatos proféticos sobre el progreso y la democracia. La normalización de las redes internacionales del telégrafo, el correo y el dominio de las "máquinas voladoras" (aviones), en conjunto, reavivan los impulsos imaginarios de liberación humana (Mattelart, 2000:191). Asimismo se alteran las cartografías imaginarias, en un sentido desterritorializador, puesto que se lanzan proclamas en las que el universo - se especula- debería constituir un solo territorio. Durante la reunión llevada a cabo en París, el 13 de abril de 1865, para la creación de una Unión Telegráfica Internacional, el ministro francés de Asuntos Exteriores concibe la reunión como un verdadero congreso de la paz, pues la comunicación instantánea que trae el telégrafo terminará con los malentendidos causantes de la guerra. Ese hilo eléctrico (del telégrafo) "permite establecer un diálogo rápido, incesante, entre los miembros dispersos de la familia humana" (Mattelart, 2000:194). En concordancia con esta iniciativa, entre 1874 y 1878 se crea la Unión Postal Universal que suscriben veintidós Estados de Europa y América. Lo más destacable de este convenio resulta la instauración de "un territorio postal único".

Pues bien, el periodo comprendido entre 1875-1914 puede catalogarse como la etapa decisiva para resaltar la larga historia de los proyectos de integración mundial. (Mattelart, 2000:10). Los avances en las comunicaciones dan lugar a las redes técnicas, vistas como verdaderos agentes de civilización. Dijimos que los relatos que acompañan este desarrollo aluden a una estructuración del mundo sin fronteras, o dicho en los términos del geógrafo anarquista Elisée Reclus (1830-1905) — cuando reclamaba el advenimiento de la Patria Grande - la civilización tendrá "su centro en todas partes, su circunferencia en ningún lugar" (Mattelart, 2000:224). Las redes que atraviesan el planeta simbolizan la interdependencia y el internacionalismo. El ímpetu mundialista se acrecienta con las Exposiciones Universales, inauguradas en Londres (1851). En ellas se reúnen las ramas de la actividad industrial de todas las naciones. En tanto congregación internacional, se las verá como "asambleas del progreso" en las que los hombres se hermanan (Mattelart, 2000:21). Igualmente constituyen la representación más acabada de una sintaxis cultural desconocida: la fascinación por "ver en conjunto, de manera global, aquello que originalmente no

alrededor de 1900; sin embargo, no se generalizaron sino hasta 1920 e, incluso, principalmente en los Estados Unidos; 2) decenios de 1940 y 1950, cuando la televisión (inventada en la década del 30) y la aviación comercial se volvieron comunes en Estados Unidos y gran parte del mundo; los ordenadores interconectados, cuyo origen fue en la década de 1960, pero despegó a comienzos de 1990. Lo comúnmente importante de estas tres oleadas es que funcionaban en redes, de ahí que, si bien tardaron en cuajar, cuando lo hicieron su propagación fue de extraordinaria rapidez. Cfr., J.R. McNeill y William H. McNeill (2004:302). 
puede conocerse sino en la sucesión". Los peregrinos de estas exposiciones provienen de culturas en las que las experiencias cotidianas han ingresado en un orden universal, "globalizante", la visita les restituye cierta revitalización de las diferencias constitutivas del mundo. Es la amalgama de lo diverso (Montaldo, 1994:28-30). La Exposición Universal remeda un "microcosmo de una humanidad que intenta dar la impresión de que se reconcilia consigo misma". Esta institución universal "intercambia con el movimiento pacífico los mismos grandes relatos sobre la concordia general" (Mattelart, 2000:237).

Como agentes civilizadores, las redes de comunicación integran un relato optimista. Por el contrario, habrá otra mirada que abstrae a las redes de ese manto de solidaridad universal con el que se encubre, viendo en ellas, de manera crítica, nada más que la interconexión de los mercados nacionales sometidos a una nueva división del trabajo y pactos de seguridad que las grandes potencias consienten para el reparto del globo. Dicho en otros términos, la imaginación utopista de concordia y unión universal le otorgaría un "rostro humanitario" al expansionismo europeo.

Distinto será el caso de América Latina: el sistema de comunicaciones está apenas desarrollado, lo que, desde luego, redunda en perjuicio de las ideas integracionistas, problema que había sido identificado por Manuel Ugarte tempranamente: "Debido a la escasez de ferrocarriles, telégrafos y líneas de navegación, estos países se han desarrollado tan independientemente los unos de los otros, que a pesar de la identidad de origen y la comunidad de esperanzas, evolucionan en órbitas distintas. Sólo los más vecinos están en contacto" (1910:94). Desde luego que esta deficiencia, mientras que por un lado redobla el aislamiento e imposibilita la visión de conjunto, por el otro, el sistema de comunicación funciona eficazmente en relación con el resto del mundo, con el que los países latinoamericanos están unidos a través de "maravillosas vías de comunicación". Más aún, razona Ugarte, es mayor el conocimiento de lo que pasa en China, pero se ignora lo que ocurre en el propio continente (1910:94). Con todo, países más adelantados en cuanto a las comunicaciones, como el caso de Argentina, habían tomado el asunto como una política de Estado por la envergadura de sus efectos. El argentino Gervasio Antonio de Posadas fue Director General de Correos durante 1862-1874 y llegó a convertirse en un hombre señero dentro de la historia de las comunicaciones. Su sucesor, Eduardo Olivera, que presidirá la Dirección de Correos y Telégrafos entre 1874 y 1880, no cejará en los esfuerzos por reorganizar y modernizar las comunicaciones. Tal era la importancia asignada a la tarea que le solicitó al Presidente de la Nación mantener a la repartición pública fuera de los avatares políticos, a fin de llevar con tranquilidad la tarea impuesta. En "La Reorganización del Correo Argentino" (1909) dirá que "contribuir a facilitar la comunicación entre todos los hombres de la tierra era algo grandioso y digno de un hombre que sólo anhelaba el bien de su 


\section{Claudio Maíz}

país, propendiendo, en lo posible, a la fraternidad de las ideas y sentimientos de la humanidad" (Bose, 1966:589). Como se puede observar, también en estas latitudes el discurso mundialista se deriva del impacto que el desarrollo de las comunicaciones produce en la visión planetaria. ${ }^{8}$

Vías férreas incipientes, inexistencia de sistemas fluviales, deplorable estado de las redes camineras no podían menos que generar la idea de la incomunicación latinoamericana, al menos, desde un punto de vista estrictamente "físico", "material". Sin embargo, durante el periodo en el cual los sistemas de comunicación adolecen de lo antes dicho, se producen sorprendentemente las más intensas redes intelectuales hasta entonces conocidas. Vale decir que la posibilidad de que emergieran estas redes no depende del deficiente sistema de comunicación "material", sino de dos soportes fundamentales: los periódicos y las revistas. Podríamos decir que las redes in praesentia están sujetas a las condiciones materiales de los sistemas de comunicación existentes, en tanto que las in absentia se apoyan en las revistas, los periódicos y las cartas.

\section{LAS POSIBILIDADES HEURÍSTICAS DE LA RED}

Existen dos vertientes principales que se han ocupado de la noción de red: por un lado, la teoría comunicacional y por otro la antropología y la sociología. Esta última es la primera en tomar metodológicamente esta noción. Concretamente, la antropología británica la incorporó a partir de la Segunda Guerra Mundial como respuesta a las limitaciones del estructural-funcionalismo para explicar las situaciones de cambios en las sociedades tradicionales y los mecanismos de articulación de las sociedades. Se atribuye a John Barnes el uso del término red (network). El valor descubierto en la noción de red consistía en que la estructura de relaciones tenía una capacidad explicativa mayor que la pertenencia a categorías sociales o grupos institucionalmente definidos. Se desarrolló una definición de red entendida como un conjunto de lazos que vinculan a los miembros del sistema social a través, y más allá, de las categorías sociales y los grupos cerrados.

En cuanto a la sociología americana, siguiendo los trabajos de Georg Simmel, tomaron como propio su argumento de que la forma de las relaciones sociales determinaba, en gran medida, su contenido. Se concluyó que el tamaño de las redes sociales y las interconexiones realizadas restringen la conducta individual y el intercambio diádico. Aún más, se concentraron en los patrones de redes antes que en su contenido, postulando que patrones similares de lazos

\footnotetext{
${ }^{8}$ El "confinamiento" a la nación (o lo que por ella se entendía promediando el siglo XIX) del dinamismo asociativo lo podemos sopesar en el trabajo de Di Stefano, Roberto, Sabato Hilda, Romero, Luis Alberto (2002).
} 
podrían tener consecuencias conductuales similares, sin importar el contexto sustantivo (Wellman, 1997).

Quisiéramos reseñar todavía una perspectiva más para dar cuenta de la amplia diversidad del abordaje de este problema. Se trata del enfoque de las redes proveniente de la historiografía de las ideas que ha sido muy eficaz en el registro, relevamiento y descripción de las redes. Aunque esta perspectiva pone el acento en el contenido eidológico que producen, antes que en la manera como lo hace, es decir, se presta poca o ninguna atención al comportamiento sistemático de las redes, a sus estructuras, surgimiento y desapariciones. Esta perspectiva está representada en gran medida por el chileno Eduardo Devés Valdés quien en Redes intelectuales en América Latina responde que se entiende por red "a un conjunto de personas ocupadas en la producción y difusión del conocimiento, que se comunican en razón de su actividad profesional, a lo largo de los años. ${ }^{9}$ Devés destaca acertadamente, entre las virtudes de las redes, la revisión de nociones como "influencias", "generación" y "campo intelectual". A la verticalidad atribuida a la relación Norte-Sur se le puede confrontar la horizontalidad Sur-Sur de las redes, con lo cual la "influencia" pierde su carácter privilegiado y hasta dogmático. Las ideas, piensa Devés, se encuentran disponibles en las redes, donde se comparten y desarrollan colectivamente. Generación y campo intelectual al relacionarse con las redes se alteran, en razón de que las edades dentro de la red no son una condición excluyente. Es decir, conviven diferentes franjas etarias ${ }^{10}$ y campo intelectual, asociado a las disputas por el poder o por el capital socio-cultural, al ponerlo en contacto con el funcionamiento de las redes, la colaboración — rasgo distintivo de la red intelectual - deja escaso o ningún lugar al conflicto o a la competencia (2007:35).

Para hacer más inteligible nuestra noción de red en su relación con la serie literaria y el momento histórico al que pretendemos articularla, podemos partir de esta definición de Castells: "Conjunto de nodos interconectados. Un nodo es el punto en el que una curva se intercepta a sí misma. Lo que un nodo

\footnotetext{
${ }^{9}$ Devés enumera, por lo menos, ocho modalidades que alertan sobre la existencia de una red y que serían los puntos de entrada para su estudio: 1 . encuentros cara a cara; 2 . correspondencia; 3 . participación en los mismos congresos, sociedades, agrupaciones; 4. prologación, comentario o presentación de libros; 5. publicación en los mismos medios; 6. participación en las mismas campañas o iniciativas; 7. diálogos, polémicas; 8. citaciones recíprocas (2007:32).

${ }^{10}$ Eugenia Molina ha planteado de manera acertada la diferencia entre estudiar las ideas de la generación romántica de 1837 en Argentina y centrarse en las relaciones y la forma como éstas influyeron en el comportamiento y el pensamiento de sus miembros. A poco de andar, la historiadora nos advierte que no podrá ser por medio del método generacional el rumbo que deberá tomar con el fin de dar cuenta de los problemas que se plantea. "La noción de "generación" — explica— tampoco permite descubrir los procedimientos por los que los individuos separados por miles de kilómetros, dispersos en el país o las naciones vecinas, pudieron pensar del mismo modo, ni tampoco el mecanismo por el que su pertenencia grupal influyó en su pensar" (2000:401).
} 


\section{Claudio Maíz}

es concretamente, depende del tipo de redes a que nos referimos" (1998:506). El soporte tecnológico que interviene como base de esta definición opera a velocidad de la luz. Esta circunstancia constituye la primera gran diferencia que se puede destacar con respecto a los soportes tecnológicos existentes en el funcionamiento de otras redes. Por caso, la red de los modernistas hispanoamericanos pertenece a la era de la comunicación no instantánea y con evidentes retardos en el tiempo, como el correo postal y el cablegrama.

Pese a todo, la lógica del enlace de la red funciona de idéntica manera, cualquiera sea el soporte tecnológico existente, es decir, acerca (acorta la distancia) entre los miembros o nodos de la misma red. ${ }^{11}$ A fin de cuentas, las distancias están en relación directa con la pertenencia o no pertenencia a una red. El otro valor destacable es el carácter transversal, en razón de que atraviesa las estructuras sociales, económicas, políticas o culturales. Para que este funcionamiento sea posible se requiere de la existencia de un código de comunicación común y compartido, como lo son, por ejemplo, ciertos valores o metas de actuación. La inclusión/exclusión a la red depende, pues, de este requisito. Aunque por definición, las redes son estructuras abiertas, la incorporación a una de ellas supone la aceptación de los fundamentos que le dan origen y sentido. Sin embargo - y desde luego - no se trata ni del único punto de partida ni tampoco de la única definición posible. Mucho menos se sostiene, aquí, que la única perspectiva válida sea la de la Teoría comunicacional. ${ }^{12}$

\section{LA TRANSFERENCIA DE “LO MODERNO” EN HISPANOAMÉRICA}

Así las cosas, una perspectiva de interés para nosotros tiene que ver con una mirada multidisciplinaria y con el propósito de creación de un estatuto propio a lo que se da en llamar una "ciencia de las redes". Nos referimos a Duncan J. Watts y su trabajo Seis grados de separación. La ciencia de las redes en la era del acceso (2003) que aborda la cuestión de las redes desde una mirada que procura conciliar las matemáticas, la física y las ciencias sociales en el estudio del comportamiento de las redes. En los marcos del pensamiento complejo - espacio epistemológico en el que mejor se acomoda una ciencia de

\footnotetext{
${ }^{11}$ Sin embargo, comparten algunas características, como las que surgen del análisis de Castells: "La tipología definida por las redes determina que la distancia (o intensidad y frecuencia en la interacción) entre dos puntos (o posiciones sociales) sea más corta (o más frecuente, o más intensa) si ambos son nodos de una red que si no pertenecen a la misma. Por otra parte, dentro de una red determinada los flujos no tienen distancia, o es la misma, entre los nodos. Así pues, la distancia (física, social, económica, política, cultural) para un punto o posición determinados varía entre cero (para cualquier nodo de la red) e infinito (para cualquier punto externo a la red)" (1998:506).

${ }^{12}$ La noción de red tiene un uso en diferentes disciplinas, como la psicología social donde indica el universo relacional de una persona, es decir, el conjunto de relaciones y estructuras de apoyo socioafectivo de cada una; la psicología social identifica las características estructurales de las redes: el tamaño, la densidad, la composición (distribución), la dispersión, la homogeneidad/heterogeneidad y tipos de funciones que ejercen (Fleury, 2002).
} 
las redes - los epifenómenos de la cultura literaria no pueden pensarse simplemente desde una perspectiva unilateral, cualquiera sea ella y la relevancia, aceptación y prestigio que haya conseguido. Watts, valiéndose de la teoría matemática de los grafos, sostiene que la divisoria entre aislamiento y conectividad es un importante umbral para que la información, las enfermedades, el dinero, las innovaciones, las modas y tendencias culturales alcancen a circular. Sin embargo, a diferencia de los grafos aleatorios, Watts sugiere que las redes no poseen ese carácter azaroso. De ahí que destaque el dinamismo de las redes como su principal rasgo, contrariamente a lo que los estudios sobre redes han insinuado, es decir, se trata de "encarnaciones congeladas" de fuerzas sociales, consideradas como "meros conductos" a través de las cuales se propaga, por caso, la influencia (2003:51). Otro aspecto destacable del enfoque de Watts es el énfasis que imprime a la idea de la carencia de centralidad en las redes, ya que, como postula, "el centro surge sólo como una consecuencia del acontecimiento mismo". De esa forma, el dinamismo de las redes se corresponde, a fin de cuentas, con la interacción entre iguales (Watts, 2003:54). Sin que todavía podamos sacar conclusiones definitivas, estas sugerencias redundan en nuestro estudio, puesto que nos dejan mejor posicionados para admitir como algo muy relevante la ausencia de una centralidad, de donde se desprende que las jerarquías atribuidas a una cultura sobre otra, interactúan se anulan o mitigan. Por otro lado, el hecho de no presentar las redes como meros instrumentos de propagación permite la afirmación, entonces, de que no sólo "aquello que sucede" sino "el modo en que lo hace" dependen de la red (Watts, 2003:30). En definitiva, tanto el comportamiento individual como el del sistema en un todo se ven afectados en la estructura de las relaciones. Pensar los movimientos culturales (literarios, artes visuales, arquitectónicos, etc.) desde la perspectiva de un dinamismo en red posibilita sortear el estudio estático, fuera de las oscilaciones del campo más amplio en el que se desarrollan. A su vez, la pregunta por el ¿qué son esos movimientos? (modernismo, criollismo, vanguardismo) se trueca por la de ¿cómo llegaron a producirse?; es decir, tratar de verlos en su estado de producción y no tan sólo como productos. ${ }^{13}$

Aún es posible destacar algunas nociones más, aportadas por Watts. Por un lado la noción de percolación ("penetración lenta de las aguas meteóricas en el suelo", de acuerdo al diccionario) y las reglas del umbral. En el primer caso, la teoría de percolación ha sido aplicada al estudio de las epidemias. Los

\footnotetext{
${ }^{13}$ Resulta, por demás, pertinente aquella distinción operativa que hiciera Raymond Williams entre "instituciones" y "formaciones" para el estudio de las relaciones sociales efectivas de la cultura. El riesgo - piensa Williams - de deducir relaciones culturales significativas o, incluso, causales sólo a partir del estudio de las instituciones es que se puede pasar por alto el "sorprendente fenómeno del 'movimiento' cultural tan importante en el periodo moderno" (Raymond, 1981:33).
} 


\section{Claudio Maíz}

modelos percolativos parten de la idea de que todos los nodos tienen la misma probabilidad de ser susceptibles. No obstante, como lo reconoce Watts, las redes del mundo real son más complejas que cualquier modelo aleatorio, ya que aquellas se caracterizan por la heterogeneidad. Así, sobrepasando la estática versión de la teoría de la percolación, Watts se refiere a los fenómenos de propagación de ideas o innovaciones como "cascadas". De tal manera que la "difusión de las ideas, por tanto, a diferencia de la extensión de las enfermedades, requiere un equilibrio entre la cohesión en el interior de los grupos y la conectividad entre ellos" (2003:232), a partir de un ciclo de la innovación.

En nuestra red de individuos, cada uno tiene un umbral interno y un conjunto de vecinos de red a los que presta atención. Al principio del ciclo de innovación, una única innovación emana de algún lugar de la red, y luego, antes de que el ciclo termine, tiene que pasar una de dos: o bien la innovación cae en desuso; o bien eclosiona en una cascada de información (2003:236).

Tales miradas permiten obtener algunas respuestas al modo como las tendencias estéticas se propagan. Asimismo, estas perspectivas nos obligan a reformular nuestra idea sobre las relaciones de causa y efecto en la historia y, por ende, en los procesos culturales que nos ocupan. Según Watts, el enfoque convencional consiste en considerar que cuando alguien tiene éxito, éste es proporcional al mérito o relevancia del individuo. El éxito, sin embargo "es un descriptor que sólo se puede aplicar a posteriori"; se trata de una visión del mundo en función de los "resultados". Por el contrario, esta tendencia indica que carecen de interés aquellos resultados convertidos en fracasos (2003:245). De ahí que la recomendación de Watts sea centrarse no en el estímulo mismo, sino en la estructura de la red donde impacta. Por otro lado, las reglas de umbral mencionadas tienen que ver con la porosidad de las redes, en el sentido de que permiten la difusión de las innovaciones. La idea de la vulnerabilidad de algún nodo ayuda a explicar la manera como los innovadores logran introducir con éxito sus ideas nuevas. De ahí a la cascada no hay mucho trecho. Para que haya innovadores debe haber, desde luego, adaptadores iniciales (acólitos, apóstoles y seguidores) dice Watts (2003:233).

Un claro ejemplo de "umbral bajo", en el sentido de la vulnerabilidad que puede tener el nodo de la red, lo podemos encontrar en la explicación que Pedro Emilio Coll daba de la introducción del modernismo en la literatura americana

Hay actualmente en América un movimiento literario sobre el que caen crueles sátiras y al que críticos celosos y malhumorados tratan de detener en nombre de la tradición y del buen sentido. Por un momento se creyó pasajera nube de verano, mera cuestión de moda; pero se generaliza y persiste demasiado para creerlo. Efímeras revistas que mueren, faltas de 


\section{La eficacia de las redes en la transferencia de bienes simbólicos}

lectores, entre espasmos líricos; adolescentes que cuentan sus ensueños en poemas vagarosos, en prosas complicadas, y esto, no uno ni en una sola nación, sino muchísimos y en todo el continente.

Se atribuye a la moda, a la moda que nos viene de París, junto con las cortas y los figurines de trajes; pero, aun así, podría argüirse que una moda extranjera que se acepta y se aclimata es porque encuentra terreno propio, porque corresponde a un estado individual o social y porque satisface un gusto que ya existía virtualmente. Hasta los nuevos modelos de vestidos y los colores en boga son determinados por el ambiente de ideas y sentimientos de una época ¿y no ha de serlo la literatura? Si se aclaran o se oscurecen los tintes de las telas, es de acuerdo con la estación del año; cada vaivén de la moda indica una variación en el termómetro social; también las maneras de pensar y de escribir están sometidas a la temperatura moral. Si París impone hoy sus modas, es porque satisfacen íntimas afinidades de los pueblos que las adoptan; cambian esas afinidades, y entonces nos vendrá de Londres o de Nueva York las ideas y los patrones de modistas, hasta que nosotros podamos exportarlos (Coll, 1901).

Esta larga cita que extraemos del ensayo del crítico y escritor venezolano Pedro Emilio Coll, de comienzos del siglo XX, exige formularnos, por un lado, algunas interrogantes en torno a los sistemas de religación, funcionamiento $\mathrm{y}$ alcances de los mismos y, por el otro, procurar determinar el grado de conciencia alcanzado por los intelectuales sobre el desarrollo de las redes. Esto último en razón de que los niveles de conocimiento sobre la manera como se llevan a cabo las tareas intelectuales, por encima de las distancias geográficas, nos proveen una mayor información en la gestación y desenvolvimiento de las relaciones.

Podemos retomar algunas de las nociones explicitadas con anterioridad. En efecto, la teoría del actor-red subraya la importancia de la circulación de información en el comportamiento de la sociología de las asociaciones. El comportamiento no es sólo de orden sociológico sino que, también, discursivo. El doble estándar del funcionamiento de las transferencias implica que, inicialmente, no sean las obras las portadoras de innovaciones. Son los individuos los que intercambian información o representaciones en una red. Michel Espagne y Michael Werner (2008) reconstruyen la referencia cultural alemana en Francia entre la segunda mitad del siglo XVIII y el comienzo de la Primera Guerra Mundial. En la génesis de la transferencia se hace evidente la presencia de redes que facilitan el desplazamiento. Estos investigadores le atribuyen tal relevancia a la red que plantean que toda una serie de producciones ideológicas tenidas como hito tienen una génesis colectiva, con lo cual queda cuestionada la noción de autor. El ejemplo que presentan es el de Víctor Cousin (París, 1792-Cannes, 1867) y la red de interlocutores que crea. El filósofo francés, en virtud de los ecos del debate filosófico en Alemania, se presenta como un "verdadero personaje colectivo", dando la impresión de "una 


\section{Claudio Maíz}

verdadera disolución del sujeto en el sistema" (Espagne y Werner, 2008:210). Lo que reviste mayor implicancia para nuestra argumentación es que se considera a las redes como "espacios matriciales" anteriores a cualquier producto cultural determinado, pero que "tienden a sobrepasar el estadio de intercambio epistolar u oral para constituirse como textos" (Espagne y Werner, 2008:211). Volvamos a la cita de Pedro Emilio Coll tomando en cuenta los juicios anteriores. El movimiento literario que Rubén Darío patrocina como modernismo es irrefrenable pese a las "sátiras" y "críticas" que sobre él recaen. Al igual que una mancha de aceite se extiende entre los jóvenes y todos los países del continente. Frente a semejante ímpetu, cabe preguntarnos si no es una moda (aunque algo de ello pueda haber) ¿Cómo ha sido factible la expansión de la novedad estética, basada en el simbolismo principalmente? Respondamos con las mismas palabras de Coll "es porque encuentra terreno propio, porque corresponde a un estado individual o social y porque satisface un gusto que ya existía virtualmente". Lo que más llama la atención entonces es la existencia virtual de un terreno fértil o bien para satisfacer una necesidad de renovación o bien para ingresar a un mercado literario de mayor dimensión, o ambas cosas a la vez. De lo que no caben dudas es que los "espacios matriciales" están operando anticipadamente para que llegue a producirse el fenómeno de cambio. Dicho de otro modo, la red de los modernistas ha creado las condiciones necesarias para la admisión de la novedad estética. De esta manera se estaría dando cumplimiento a la hipótesis de una génesis colectiva del discurso, "de un borrador colectivo", que "permite articular la categoría de red y la de ideología como discurso fijado en los textos" (Espagne y Werner, 2008:212).

\section{ALGUNAS CONCLUSIONES}

Hemos dicho, en otro lugar, que los intercambios de bienes simbólicos a través de las redes ponen en duda su pertenencia a algún lugar en particular. La propia virtualidad en la que viven tales bienes simbólicos (ideas, gustos, tendencias) derrumba la hipótesis de que una idea sea "propiedad" de un sujeto en particular, así como que se hallen anclados a un lugar determinado. He aquí el motivo fundamental que nos advierte de las precauciones sobre cómo se debería escribir una historia ya no de los acontecimientos sino, de los problemas. Una perspectiva como la de las redes podría - junto con una visión menos "esencialista" de las ideas, siendo en su lugar más propicia una visión semiótica - resolver la pertenencia y, por tanto, la propiedad o no propiedad de una idea a un lugar determinado. Todo ello con el fin de poner en discusión las nociones de imitación o influencia en la historia del modernismo o de los comportamientos culturales latinoamericanos, en general. En el sentido indicado, la historiografía de las ideas, si adopta la metodología de las redes, no puede obviar la dimensión tanto lingüística y básicamente pragmática de los discursos eidológicos, a riesgo de volver a caer en la presuposición de que a una 


\section{La eficacia de las redes en la transferencia de bienes simbólicos}

idea le corresponde un sujeto y un espacio particular de producción. Por eso, las redes debilitan la concepción de autor y ponen en crisis, asimismo, la producción cultural inserta en una nación. ${ }^{14}$

La red, en tanto "formación cultural", está constituida por un conjunto de individuos que establecen relaciones entre sí a través de un interés particular: literario, político, programático, etc., pero que no comparten, permanentemente, un mismo espacio. Estas lógicas de enlaces son diferidas y a distancia, por lo menos, en un determinado periodo del desarrollo tecnológico comunicacional. En efecto, algunas de las redes literarias, sociales o políticas específicas están enlazadas a los medios técnicos con los que se cuenta. De modo que, como un rasgo estructural de las redes, anotamos la existencia de un nexo vinculante entre desarrollo tecnológico y características de la red, aunque dicha propiedad sea problemática.

El código de comunicación común y compartido es el requisito obligatorio que posibilita el funcionamiento de la red, animando la conexión entre los miembros. En cuanto a la red que estudiamos, podríamos decir que una imposición doble del código activa los enlaces. Por una parte, la red como un "actor colectivo" se torna en sí misma una estrategia geopolítica duramente el modernismo, por cuanto propaga la producción de los miembros que la componen. Pero, también, sería factible indicar una fuerza superior que impele los emprendimientos asociativos por medio de redes. Se trata de los impulsos libertarios provenientes desde Europa, secundados por el desarrollo de los medios técnicos de comunicación. Un espíritu de concordia anima la producción de discursos utópicos sobre la unidad mundial. Podríamos decir, entonces, que el código matriz compartido en la red de intelectuales que estudiamos se despliega en dos planos: uno, endógeno, reúne las problemáticas propias del movimiento intelectual de la modernización latinoamericana, otro, exógeno, proviene de los relatos emergentes de la revolución comunicacional que se está produciendo en el Hemisferio Norte. En fin, el triunfo del modernismo como cambio estético sobre otras variables tiene en la noción de actor-red una de las principales explicaciones. Los mecanismos utilizados — revistas, contactos epistolares, etc. - anteceden y preparan el escenario para que la transferencia sea una realidad exitosa.

\footnotetext{
${ }^{14}$ Un enfoque de estas características se ocupa del análisis del pensamiento involucrado en movimientos, en la acción histórica y el papel que juega en esos procesos. La pregunta que constituye el punto de partida de este tipo de abordaje puede formularse de este modo: ¿Cuánto de lo que sucede históricamente es determinado por el conjunto de circunstancias dentro de las cuales se piensa y cuánto procede de los efectos del pensamiento sobre el comportamiento de los seres humanos individual o colectivamente considerados? Esto supone entonces un trabajo de inserción de las manifestaciones del pensamiento en el comportamiento sociohistórico. En ese marco, el pensamiento nos es accesible en lo que llamamos "hechos del discurso", que están inscritos en hechos materiales que pueden ser libros, diarios, panfletos, volantes, imágenes, documentales, etc. Esta línea de razonamiento puede seguirse en Altamirano (2005).
} 
CONICET-Universidad Nacional de Cuyo*

Ciudad Universitaria Parque General

Facultad de Filosofía y Letras

Departamento de Letras

San Martín Mendoza 5500 (Argentina)

cmaiz@logos.uncu.edu.ar

BIBLIOGRAFÍA

Altamirano, Carlos. Para un programa de historia intelectual y otros ensayos. Buenos Aires: Siglo XXI, 2005.

Anderson, Benedict (1997). Comunidades imaginadas. Reflexiones sobre el origen y la difusión del nacionalismo. Trad. Eduardo Suárez. México: F.C. E., 2005.

Arellano Hernández, Antonio. "La sociología de las ciencias y de las técnicas de Bruno Latour y Michel Callon", en Cuadernos digitales: publicación electrónica en historia, archivística y estudios sociales. V. 8. $\mathrm{N}^{\mathrm{o}} 23$ (2003). Universidad de Costa Rica. Escuela de Historia. http://historia.fcs.ucr.ac.cr/cuadernos/c23his.htm (acceso diciembre de 2010).

Bose, Walter. "Historia de las comunicaciones", en Historia Argentina contemporánea. 1862-1930. Vol. III. Buenos Aires: El Ateneo, 1966.

Briggs, Asa; Burke, Peter. De Gutenberg a internet. Una historia social de los medios de comunicación. Trad., de Marco Aurelio Galmarini, Madrid: Taurus, 2002.

Castells, Manuel. La era de información. Economía, sociedad y cultura. Vol.1. Vers. castellana de Carmen Martínez Gimeno. Barcelona: Alianza, 1998.

Castells, Manuel. Hacia un Estado Red. Globalización e instituciones políticas en la nueva época de la información. Ponencia presentada en el Seminario Sociedad y Reforma del Estado. Ministerio de Administración Federal de Reforma do Estado, Sao Paulo, 1998.

Coll, Pedro Emilio. "Decadentismo y americanismo", en El castillo de Elsinor, Caracas, 1901.

Devés Valdés, Eduardo. Redes intelectuales en América Latina. Hacia la constitución de una comunidad intelectual. Santiago de Chile: Instituto de Estudios Avanzados, Universidad de Santiago de Chile, 2007.

Di Stefano, Roberto, Saabato, Hilda y Romero, Luis Alberto. De las cofradias a las organizaciones de la sociedad civil. Historia de la iniciativa asociativa en Argentina 1776-1990. Buenos Aires: Gadis, 2002. Versión electrónica: http:// www.confinesociales.orga/pdfs/HistodelasAsociaciones.pdf

Espagne, Michel; Werner, Michael. "La construcción de una referencia cultural alemana en Francia. Génesis e historia (1750-1914), en Sanz Cabrerizo, Amelia (comp.), Intercultural/Transliteraturas. Madrid: Arco Libros, 2008.

Fernández Bravo, Álvaro (en prensa). "Redes atlánticas y mundo tropical: Pedro Henríquez Ureña, Alfonso Reyes y María Rosa Oliver en la diáspora americanista", en Wasserman, Claudia y Devés-Valdés, Eduardo. Pensamento latino-americano: além das fronteiras nacionais. Porto Alegre: Editora da Universidade Federal do Rio Grande do Sul.

Ferrer, Aldo. Historia de la globalización. Orígenes del orden económico mundial. Buenos Aires: F.C.E., 1996. 
Fleury, Sonia. "El desafío de la gestión de las redes de políticas", en Revista Instituciones y Desarrollo $\mathrm{N}^{\circ}$ 12-13, 2002.

Foucault, Michel. Las palabras y las cosas. Una arqueología de las ciencias humanas. Trad. de Elsa Cecilia Frost, $1^{\text {a }}$ edición en español 1968, México: Siglo XXI, 1988.

Laclau, Ernesto; Chantal Mouffe. Hegemonía y estrategia socialista. Hacia una radicalización de la democracia. Madrid: Siglo XXI de España, 1987.

Maíz, Claudio. "La 'realidad' como fundamento y la eficacia de las ideas: el caso del antimodernismo literario", en Cuadernos Americanos $\mathrm{N}^{\circ} 120$ (2007) ab-jun.

Mattelart, Armand. Historia de la utopia planetaria. De la ciudad profética a la sociedad global. Trad. de Gilles Multigner. Barcelona: Paidós, 2000.

McNeill, R.; McNeill, William H. Las redes humanas. Una historia global del mundo. Trad. de Jordi Beltrán. Barcelona: Crítica, 2000.

Molina, Eugenia. "Aportes para un estudio del movimiento romántico argentino desde la perspectiva metodológica de redes (1830-1852)", en Universum, Universidad de Talca, $\mathrm{N}^{\circ} 15$ (2000).

Montaldo, Graciela. La sensibilidad amenazada. Fin de siglo y modernismo. Rosario: Beatriz Viterbo Editora, 1994.

Olson, D.R.; Hildyard, A.; Torrance, N. Literacy, language, and learning: The natural and consequences of reading and writing. Cambridge: University Press, 1985.

Olson David R.; Nancy Torrance (Comp.). Cultura escrita y oralidad. Barcelona: Gedisa, 1998.

Palti, Elías. El problema de 'las ideas fuera de lugar' revisitado. Más allá de la 'historia de las ideas'. México: UNAM, Centro Coordinador y Difusor de Estudios Latinoamericanos, 2004.

Prochasson, Christophe . Les intellectuels, le socialisme et la guerre. Paris: Seuil, 1993.

Roig, Arturo Andrés. "El Siglo XIX latinoamericano y las nuevas formas discursivas", en $E l$ pensamiento latinoamericano en el siglo XIX. México: 1986.

Rotker, Susana. La invención de la crónica. Buenos Aires: Letra Buena, 1992.

Schwarz, Roberto. "Las ideas fuera de lugar", en Absurdo Brasil: polémicas en la cultura brasilera Otilia Arantes et al. Compilación y traducción a cargo de Adriana Amante y Florencia Garramuño, $1^{\mathrm{a}}$ ed. Buenos Aires: Biblos, 2000.

Telles, Renata (2004). "Latino-americanismo e orientalismo: Roberto Schwarz, Silviano Santiago e Edward Said", en Terra rosa e outras terras. Revista de Estudios Literários, vol. 4. 2004:71-77. http://uel.br/cch/pos/letras/terranova.

Ugarte, Manuel. El porvenir de América Latina. Buenos Aires: Indoamérica, 1910.

Watts, Duncan J. Seis grados de separación. La ciencia de las redes en la era del acceso. Trad. de Ferran Meler-Ortí. Barcelona: Paidós, 2003.

Weber Max. Ensayos sobre metodología sociológica. Buenos Aires: Amorrortu, 1982.

Wellman, Barry. "El análisis estructural de las redes sociales: del método y la metáfora a la teoría y la sustancia”, en Debates en Sociología No 22 (1997) Lima: Universidad Católica PUCP.

Williams, Raymond. Cultura. Sociología de la comunicación y el arte. Trad. de Graziella Cantó. Barcelona: Paidós, 1981. 